原 著

\title{
脳幹部海綿状血管腫の戦略的顕微鏡手術アプローチ
}

\author{
村上 謙介 ${ }^{1}$, 上之原広司 ${ }^{2}$, 野下 展生 ${ }^{3}$, 遠藤 俊毅 ${ }^{4}$, 冨永 悌二 ${ }^{5}$
}

\section{Microsurgical Approaches and Strategies for the Resection of Brainstem Cavernous Angiomas}

\author{
Kensuke Murakami, M.D., Ph.D. ${ }^{1}$, Hiroshi Uenohara, M.D., Ph.D. ${ }^{2}$, \\ Nobuo Noshita, M.D., Ph.D. ${ }^{3}$, Toshiki Endo, M.D., Ph.D. ${ }^{4}$, and Teiji Tominaga, M.D., Ph.D. ${ }^{5}$ \\ ${ }^{1}$ Department of Neurosurgery, Aomori Prefectural Central Hospital, Aomori, ${ }^{2}$ Department of \\ Neurosurgery, Sendai Medical Center, National Hospital Organization, Sendai, Miyagi, \\ ${ }^{3}$ Department of Neurosurgery, Saitama Red Cross Hospital, Saitama, ${ }^{4}$ Department of \\ Neurosurgery, Kohnan Hospital, and ${ }^{5}$ Department of Neurosurgery, Graduate School of Medicine, \\ Tohoku University, Sendai, Miyagi, Japan
}

Summary: We reviewed eight patients presenting with brainstem cavernous angiomas for whom microsurgical approaches were employed. The lesions were located in the dorsal midbrain in two patients, dorsal pons in two patients, ventral pons in three patients, and dorsal medulla oblongata in one patient. Microsurgical resection was performed via the occipital transtentorial approach for the dorsal midbrain lesions, the telovelar approach for the dorsal pons and medulla oblongata lesions, and the posterior transpetrosal approach for the ventral pontine lesions. Post-operative neurological status was either unchanged or improved in all cases. Establishment of the surgical corridor and a wide viewing angle for the lesion is an essential strategy to safely excise the brainstem cavernous angiomas with functional preservation of the surrounding vital neural structures.

\author{
Key words: \\ - cavernous angioma \\ - brainstem \\ - surgical approach \\ - posterior transpetrosal \\ approach
}

Surg Cereb Stroke

(Jpn) 47: 260-265, 2019

\section{はじめに}

出血を繰り返し, 神経脱落症状の進行を呈する脳幹部海 綿状血管腫では, 外科治療を積極的に考慮する必要があ $3^{2(4) 7) 9)}$ ，脳幹切開が不可避であり，非全摘では目的をな し得ない海綿状血管腫の摘出手術において, 病変周囲の正 常神経構造を障害することなく残存機能を温存するために は, 精細な摘出手技はもちろんのこと, それを可能にする 顕微鏡手術アプローチが手術戦略上の重要な因子の 1 つと いえる。本稿では，筆頭著者がこれまで摘出術を行った脳
幹部海綿状血管腫を提示し, 安全な顕微鏡手術アプローチ 選択と手術手技の工夫について文献的考察とともに報告す る.

\section{症例・方法}

症例は 2004 年以降に摘出術を行った脳幹部海綿状血管 腫 8 例である. 病変に最短で到達できる部位に脳幹切開を 行うこととし, それを可能とする顕微鏡手術アプローチを 選択した。手術ナビゲーションは症例 1-6で用いたが，神 経生理学的モニタリングは行っていない. 術前後の神経学

1青森県立中央病院 脳神経外科, ${ }^{2}$ 国立病院機構仙台医療センター 脳神経外科, ${ }^{3}$ さいたま赤十字病院 脳神経外科, ${ }^{4}$ 広南病院 脳神経外 科, ${ }^{5}$ 東北大学大学院 神経外科学分野(受稿日 2017. 12. 7) (脱稿日 2018. 3. 27) 〔連絡先： $\overline{0} 030-8553$ 青森県青森市東造道 2-1-1 青森県 立中央病院 脳神経外科 村上謙介] [Address correspondence: Kensuke MuRAKAMI, M.D., Ph.D., Department of Neurosurgery, Aomori Prefectural Central Hospital, 2-1-1 Higashi-tsukurimichi, Aomori, Aomori 030-8553, Japan] 

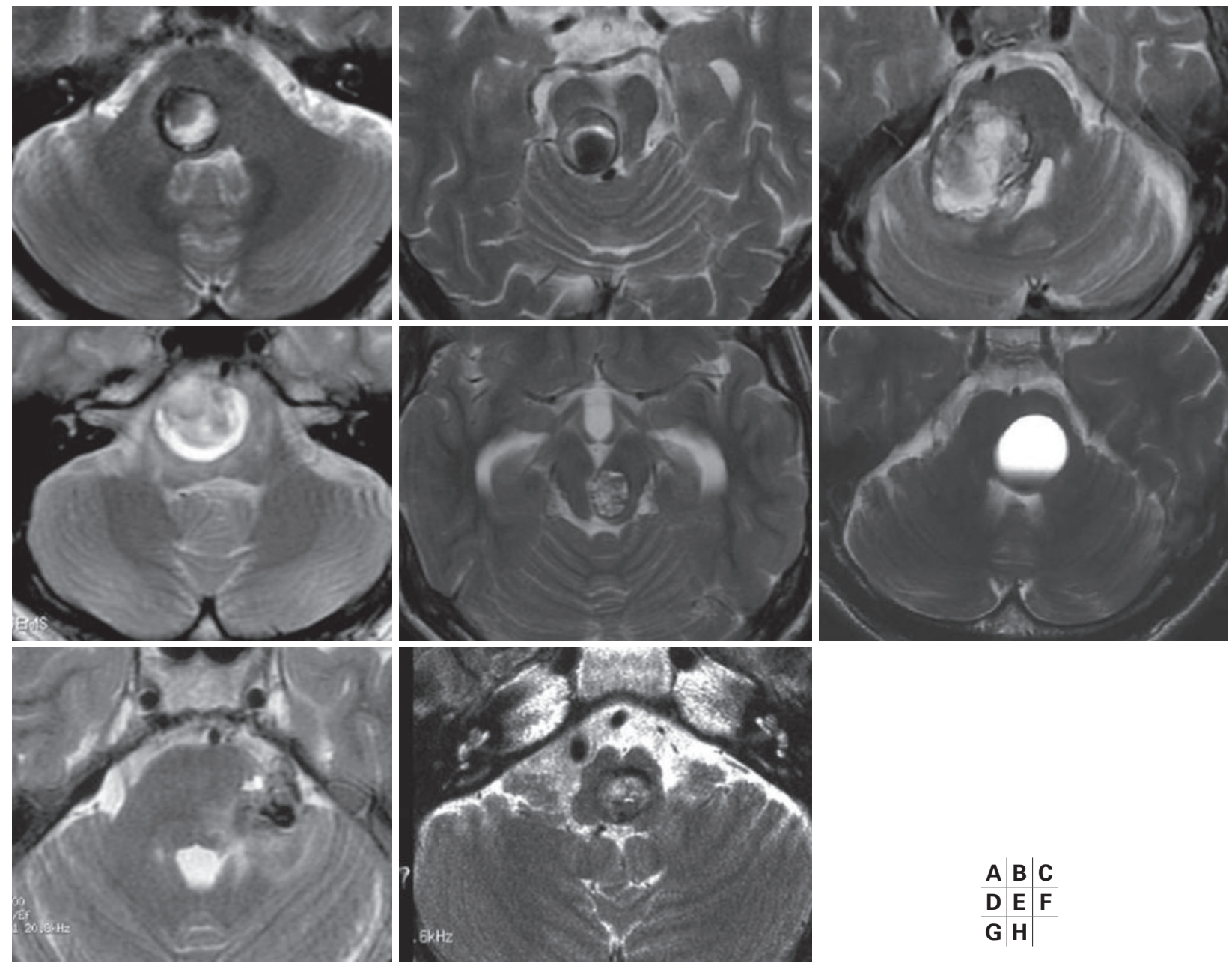

Fig. 1 T2-weighted images of the cavernous angiomas in the Cases 1-8 (A-H).

的所見，手術アプローチとその治療成績について後方視的 に検討した。

\section{結果}

8 症例の年齢は 15-78 歳で, 男性 5 例, 女性 3 例。海綿 状血管腫の部位は, 中脳背側 2 例, 橋腹側 2 例, 橋外側 1 例, 橋背側 2 例, 延髄背側 1 例であった(Fig. 1, Table 1). 術前の症候性出血は, 1 回が 1 例, 2 回が 3 例, 3 回が 2 例 で, 2 例は段階的な神経学的所見の悪化や出血の拡大は呈 さず, 初回症候性出血後に進行性の悪化, 拡大を示した. 合併する静脈性血管奇形 (developmental venous anomaly： DVA）は 4 例で認められた. DVA は, 症例 2 のみ切開を 行った脳幹表面に, 他の 3 例は摘出䏶内に確認され, 全例 で温存した，顕微鏡手術アプローチは，中脳背側の 2 例に 対して occipital transtentorial approach(OTA)を, 橋腹側 の 3 例で posterior transpetrosal approach (PTPA)を, 橋 背側 2 例と延髄背側の 1 例で telovelar approach (TA)を選
択した，術後，神経学的所見の悪化や新たな症状の出現は なく, 術後 MRIにて全例で全摘と判断した，12-126 カ月 (中央值 41.5 力月) フォローアップし, 症例 8 で術後 118 カ 月に再出血を生じたが再手術は行わなかった，最終フォ ローアップ時の modified Rankin Scale は 0-2 が 5 例, 4 が 2 例であった。

\section{代表的症例}

\section{1. 症例 4}

患者は 30 歳男性. 約 1 力月前より左上肢および右顔面 の軽度運動麻痺が出現したため近医を受診。脳幹部病変が みつかったため紹介された。 1 力月後に左片麻痺が悪化 し, 構音障害も出現した. 術前, 上肢 $3 / 5$, 下肢 $4 / 5$ の左 不全麻痺， modified House and Brackmann grade 2 相当 の右顔面麻痺を認めた．MRIでは橋右腹側に類円形の病 変を認め, 辺縁は $\mathrm{T} 1, \mathrm{~T} 2$ 強調画像とも高信号, 中心部は 不均一な混合信号を示した(Fig. 1D，Fig. 2A，B)。症状出 
Table 1 Eight cases with brainstem cavernous angiomas, which were surgically resected

\begin{tabular}{|c|c|c|c|c|c|c|c|}
\hline & $\begin{array}{c}\text { Age (years)/ } \\
\text { Sex }\end{array}$ & Lesion & $\begin{array}{l}\text { Hemorrhagic } \\
\text { episode }\end{array}$ & $\begin{array}{l}\text { DVA/anatomical } \\
\text { relationship }\end{array}$ & $\begin{array}{c}\text { Preoperative } \\
\text { mRS }\end{array}$ & $\begin{array}{l}\text { Surgical } \\
\text { approach }\end{array}$ & $\begin{array}{c}\text { Follow-up period } \\
\text { (months)/mRS }\end{array}$ \\
\hline 1 & $42 / F$ & Dorsal pons & 2 & - & 4 & TA & $14 / 2$ \\
\hline 2 & 74/M & Dorsal midbrain & 1 (progressive) & +/dorsal & 4 & OTA & $12 / 4$ \\
\hline 3 & $78 / F$ & Lateral pons & 2 & $+/$ ventromedial & 4 & PTPA & $47 / 4$ \\
\hline 4 & $30 / \mathrm{M}$ & Ventral pons & 3 & +/dorsal & 2 & PTPA & $60 / 1$ \\
\hline 5 & $48 / \mathrm{M}$ & Dorsal pons & 1 (progressive) & - & 2 & TA & $36 / 2$ \\
\hline 6 & $15 / M$ & Dorsal midbrain & 1 & - & 2 & OTA & $72 / 0$ \\
\hline 7 & $41 / F$ & Ventrolateral pons & 2 & - & 2 & PTPA & $24 / 1$ \\
\hline 8 & $54 / \mathrm{M}$ & Dorsal medulla & 3 & $+/$ rostral & 4 & TA & $126 / 1^{*}$ \\
\hline
\end{tabular}

F: female, M: male, DVA: developmental venous anomaly, mRS: modified Rankin scale, TA: telovelar approach, OTA: occipital transtentorial approach, PTPA: posterior transpetrosal approach

*Hemorrhage at 118 months after surgery

現から約 2 カ月後に摘出術を行った．迷路の後方部 (外側) を削ったのち，側頭一外側後頭下を骨切りして開頭し， PTPA にて行った (Fig. 2E)。隆起した三叉神経根部の尾 側をナビゲーションガイド下に切開して病変へ到達した (Fig. 2F). 血腫除去後に, 周囲のグリオーシス組織から 剝離し, 一塊で摘出した (Fig. 2G). 摘出脉後壁に異常静 脈を認め, DVA と考え温存した。術後 MRIで海綿状血 管腫は全摘されており, 摘出腔後壁に温存した DVA が造 影され同定された (Fig. 2C，D)。左片麻瘏は一過性に悪化 し, 新たに右外転神経麻痺もみられたが, 術後 1 力月で両 者とも消失. 独歩自宅退院した. 術後 5 年の MRI では再 発，再出血はなく，左半身の突っ張り感が残っているもの の, 日常生活は自立して就労. modified Rankin Scale 1 で あった。

\section{2. 症例 8}

患者は 54 歳男性. 4 年前に頭痛の精査でみつかってい た。起立・歩行障害, 輿下・構音障害で発症した。保存的 治療で神経学的症状はいったん改善したが, 10 日後より 再び悪化. 出血病変の拡大もみられたため(Fig. 3A-C), 発症 1 カ月後に TAにて摘出術を行った. 病変は第 4 脳 室 median sulcusに達しており，同部を頭尾側に切開して 摘出した。病変外の血腫腔が狭く, 一塊には摘出でき ず, piecemeal の切除となった. 頭側に異常静脈を認め, 術前画像では同定されていなかったが合併 DVA と思わ れ，これは温存した。術後 MRIでT1 強調画像高信号は 消失し, T2 強調画像で摘出腔が髄液信号を呈しており全 摘と判断した (Fig. 3D，E)。術後一過性に讌下障害が悪化 したが改善し, modified Rankin Scale 2 で自宅退院した. 術後 9 年 10 カ月に再出血し(Fig. 3F-H), 嚥下障害を生じ たが,リハビリテーションのみ行って自宅退院した。術後 10 年 6 カ月の最終フォローアップ時には modified Rankin
Scale 1 であった.

\section{考察}

かつては手術困難と考えられていた脳幹も, 画像診断の 進歩, 機能温存を可能にした顕微鏡手術アプローチの確 立, 神経生理学的モニタリングなど手術支援の発達によ り，外科治療が考慮されるようになった，特に境界明瞭 で, 周囲正常神経構造を浸潤性ではなく圧排性に増大する 海綿状血管腫は, 脳幹の微細な機能構築を温存した切除さ え可能であれば, さまざまな脳幹部病変の中で最もその適 応があるといえるかもしれない，摘出手術の目的は，再出 血による神経学的悪化の回避であり，血管腫の残存はその リスクを残すことになる以上, 手術の目標は全摘出であ $る^{18) 99}$ ，その一方で，部位やサイズ，出血からの期間,

DVAの合併など, 予後予測因子に基づく適切な適応選択 も重要である77.

脳幹部海綿状血管腫の手術では, 精緻な脳幹切開と脳 幹内操作が重要となるが, その成否にはアプローチ選択 が大きく影響する ${ }^{1)}$. 脳幹部海綿状血管腫をはじめとする 深部病変への顕微鏡下での手術アプローチを考える場 合, 到達のためのアプローチ経路(視軸) と視野確保のた めのアプローチ角度幅(視角)の 2 つが重要と思われる. アプローチ経路の選択には, 血管腫の中心と血管腫まで 最短となる脳幹表面部位, すなわち脳幹切開部位を結ぶ 2-point method が合理的である ${ }^{3)}$. 頭蓋底に面する腹側病 変では困難となるが, その多くは外側に伸展していて真の 腹側病変は少ないともいわれており ${ }^{8)}$, 頭蓋底アプローチ を応用することにより可能になる，橋腹側病変に対する

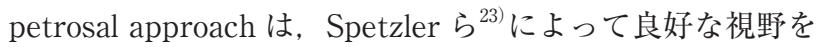
供することが報告されて以来, その有効性が支持されてい

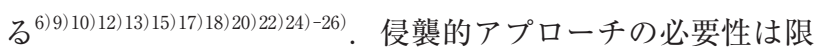
定的であるとの意見もあるが ${ }^{1 / 8)}$, 最近では正中および傍 

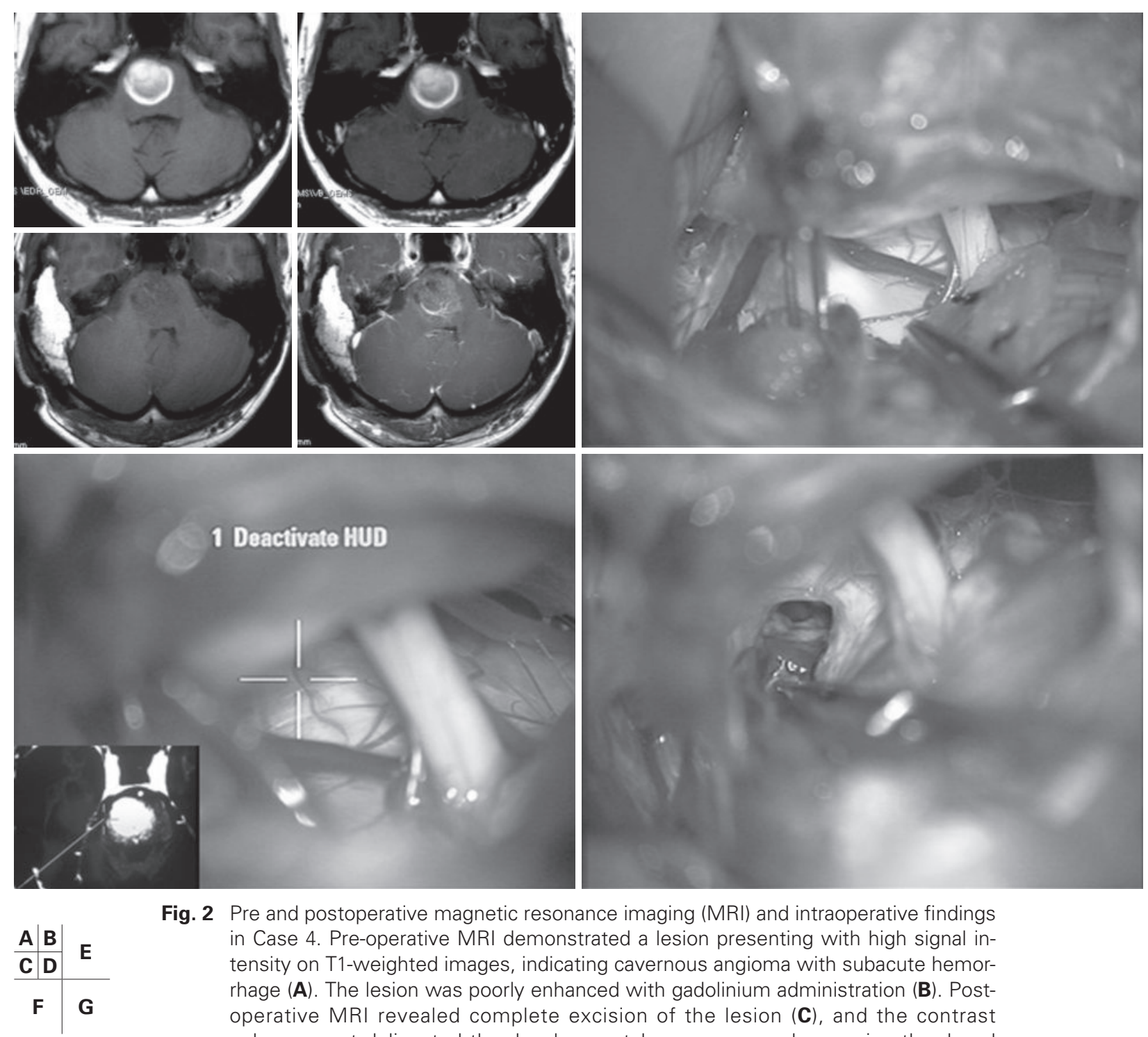

Fig. 2 Pre and postoperative magnetic resonance imaging (MRI) and intraoperative findings in Case 4. Pre-operative MRI demonstrated a lesion presenting with high signal intensity on T1-weighted images, indicating cavernous angioma with subacute hemorrhage (A). The lesion was poorly enhanced with gadolinium administration (B). Postoperative $\mathrm{MRI}$ revealed complete excision of the lesion $(\mathbf{C})$, and the contrast enhancement delineated the developmental venous anomaly coursing the dorsal surface of the resection cavity (D). The right anterolateral surface of the upper pons was exposed and was observed between the trigeminal and facial-vestibulocochlear nerve $(\mathbf{E})$. The microsurgical trajectory is indicated by the navigation guide $(\mathbf{F})$. The cavity was observed through a minimum incision of the brainstem after achieving complete resection $(\mathbf{G})$.

正中腹側病変に対する内視鏡経鼻アプローチも報告されて おり，精緻な脳幹内操作が可能であるとすれば，内視鏡経 鼻アプローチは真の脳幹腹側病変には有用かもしれな

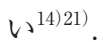

脳幹切開に関しては, 血管腫まで最短となる部位に行う ことに異論はないと思われるが, その切開口をできるだけ 小さくする工夫は, 神経核や神経路の密集した脳幹部の手 術では特別必要な配慮といえる. そのためには, 小さい切 開口から血管腫に対して広い視野角がとれることが重要で あり，顕微鏡手術では深部に視野角がとれないような狭く
直線的なアプローチは自ずと脳幹切開口の圧排, 拡大が必 要となってしまう(Fig. 4). 橋腹側病変の自験 3 例では, safe entry zone として報告されている peritrigeminal area に脳幹切開を行ったが5)19), PTPA は小さな切開口に対し て広い視野角を供した。脳幹腹側へ硬膜外に接近する anterior transpetrosal approach と比較して, 皮切線や頭蓋 底削除範囲が大きく，硬膜内に接近する点では侵襲度が高 いが, 結果的に血管腫周辺の脳幹正常構造に対して愛護的 であると筆者は考えている。一方, 中脳, 橋の背側病変で は，それぞれOTA，TAによって後頭葉や小脳テント， 

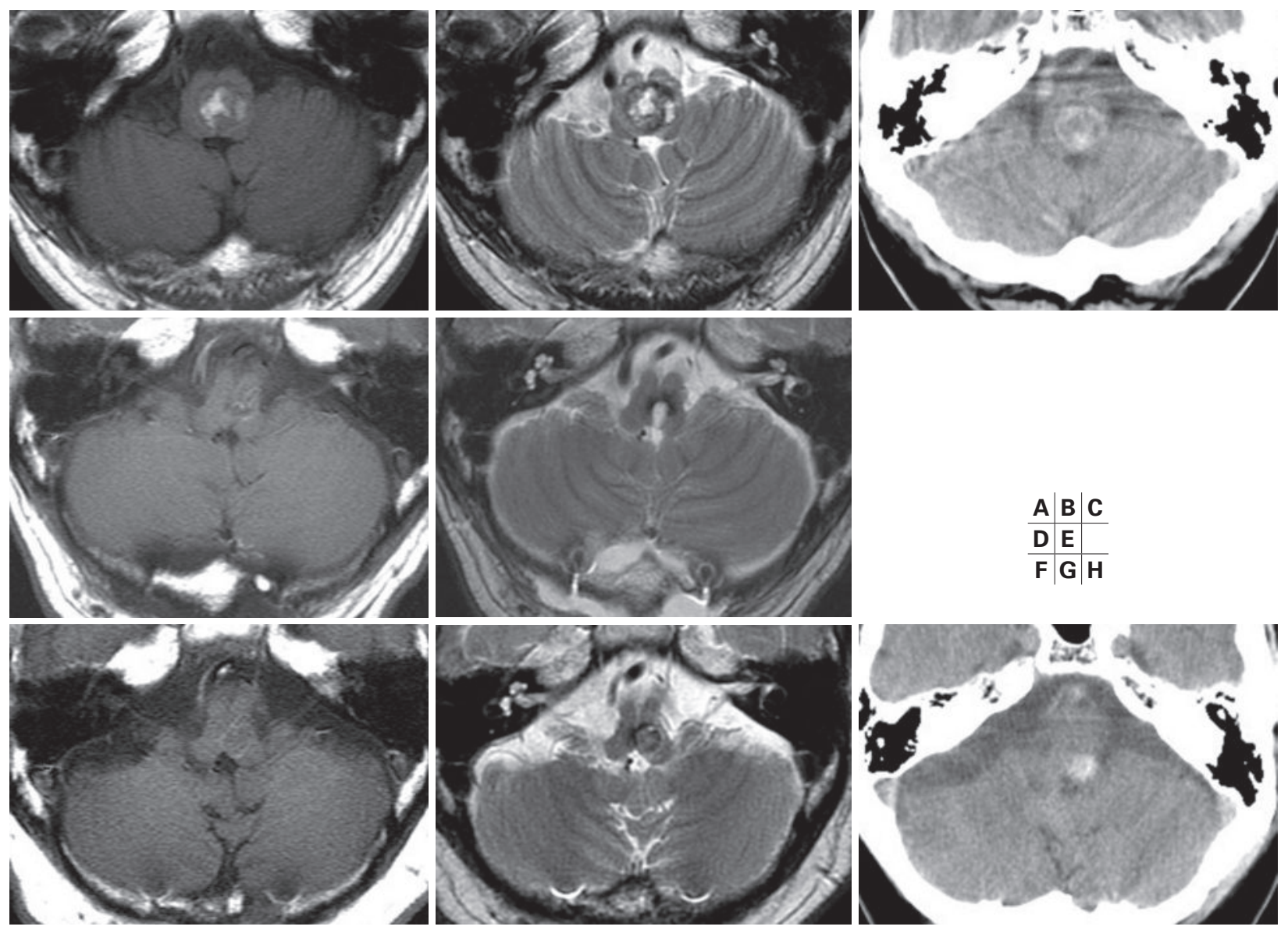

Fig. 3 Pre and post-operative magnetic resonance imaging (MRI) and computerized tomography (CT) of Case 8. Pre-operative MRI demonstrated a lesion presenting with high signal intensity on both T1 and T2-weighted images (A, B), which showed a high density in CT (C). Postoperative MRI demonstrated the excision of the lesion (D, E). Recurrent hemorrhage was observed in the MRI and CT images at 118 months after the microsurgical resection (F-H).

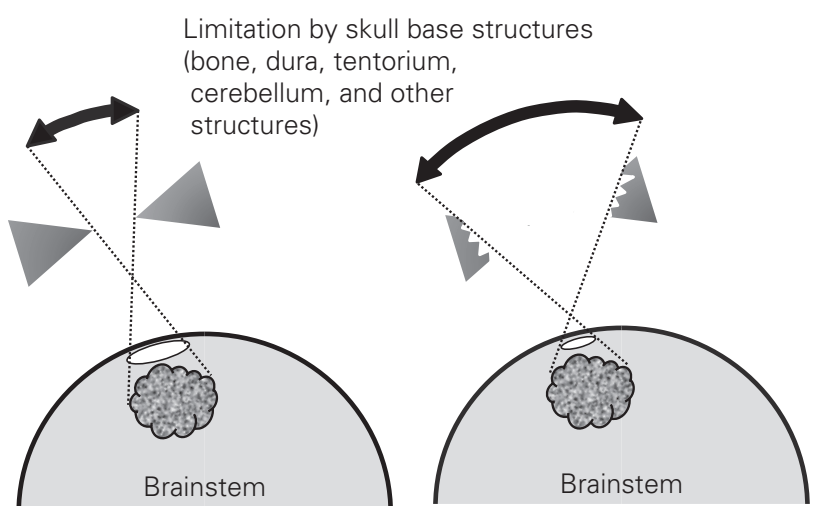

小脳をいかに避けて広い視野角を得るかが重要となる が，前者では効果的な後頭葉の牽引と小脳テントの切 開，後者では十分な脈絡裂の剝離による小脳の可動化と挛 引がそれにあたる ${ }^{16)}$ ．アプローチ経路と視角にかかわる工 夫の他に，精細でより低侵襲な脳幹内操作を可能にする方

\section{A $\mid \mathbf{B}$}

Fig. 4 An illustrative scheme showing the viewing angle through the microsurgical corridor and size of the brainstem incision. The approach trajectory is limited by skull base structures, including bone, dura, tentorium, and the overlying brain (A). A larger incision in the brainstem is required to observe the entire lesion when approaching through the limited width of trajectory. A wider approach trajectory is employed by drilling the skull base, incising the dura and the tentorium, and retracting the occipital or cerebellum effectively, which enable safe brainstem manipulation through a smaller incision (B).

法として, マイクロロール・リトラクターの使用 P $^{11)}$, 液 状化した血腫そのものを操作の緩衝として利用するための 手術タイミングの選択8) なども報告されている.

本報告 8 症例では, 10 年近い長期経過観察を行った 1 例で再出血を生じた，このことは術後 MRI で残存を同定 
できず，全摘ではなかったと判断せざるを得ない。そもそ も海綿状血管腫本体の画像描出は容易ではなく, 術前 MRI で血管腫外の出血と血管腫本体の明確な判別が難し いことが多かった. 再出血した症例 8 では唯一 piecemeal の切除を行っており, このことが摘出腔辺縁に残存させた 要因かもしれない. 全摘のためには, 血管腫周囲の血腫を 丁寧に除去してスペースをつくり, 血腫とは異なる血管腫 をグリオーシス層で剥離して一塊に切除することが重要で ある. そのためには, 小さな脳幹切開口から摘出腔内部を 広く見渡すことが重要であり, 脳幹部海綿状血管腫の顕微 鏡手術アプローチでは, 広い視野角が確保できることが大 切である。

\section{結＼cjkstart語}

脳幹部海綿状血管腫の手術について, 文献的考察ととも に自験例を報告した。病変周囲の正常神経構造に対する愛 護的操作のため, 顕微鏡手術アプローチにおいては適正な 視軸(アプローチ経路)の選択とともに広い視角の確保が重 要である. 十分な脳裂の剝離やテント切開, 頭蓋底削除に より脳幹切開部までのアプローチ経路に広い視角を確保す ることが肝要で, この観点から橋腹側病変ではPTPA が 有効であった。

本論文の要旨は，第 46 回日本脳卒中の外科学会 $(2017$ 年 3 月 : 大阪)で発表した.

\section{文献}

1) Abla AA, Turner JD, Mitha AP, et al: Surgical approaches to brainstem cavernous malformations. Neurosurg Focus 29: E8, 2010

2) Bertalanffy H, Benes L, Miyazawa T, et al: Cereberal cavernomas in the adults. Review of the literature and analysis of 72 surgically treated patients. Neurosurg Rev 25: 1-55, 2002

3) Brown AP, Thompson BG, Spetzler RF: The two-point method: evaluating brain stem lesions. BNIQ 12: 20-24, 1996

4) Dukatz T, Sarnthein J, Sitter H, et al: Quality of life after brainstem cavernoma surgery in 71 patients. Neurosurgery 69: 689-695, 2011

5) Ferroli $\mathrm{P}$, Schiariti M, Cordella R, et al: The lateral infratrigeminal transpontine window to deep pontine lesions. J Neurosurg 123: 699-710, 2015

6) François $\mathrm{P}$, Ben Ismail M, Hamel O, et al: Anterior transpetrosal and subtemporal transtentorial approaches for pontine cavernomas. Acta Neurochirur (Wien) 152: 1321-1329, 2010

7) Garcia RM, Ivan ME, Lawton MT: Brainstem cavernous malformations: surgical results in 104 patients and a proposed grading system to predict neurological outcomes. Neurosurgery 76: 265-278, 2015

8) Giliberto G, Lanzino DJ, Diehn FE, et al: Brainstem cavernous malformations: anatomical, clinical, and surgical considerations. Neurosurg Focus 29: E9, 2010
9) Gross BA, Batjer HH, Awad IA, et al: Brainstem cavernous malformations: 1390 surgical cases from the literature. World Neurosurg 80: 89-93, 2013

10) Hauck EF, Barnett SL, White JA, et al: Symptomatic brainstem cavernomas. Neurosurgery 64: 61-71, 2009

11) Ichinose $T$, Goto $T$, Morisako $H$, et al: Microroll retractor for surgical resection of brainstem cavernomas. World Neurosurg 73: 520-522, 2010

12) Kashimura $\mathrm{H}$, Inoue $\mathrm{T}$, Ogasawara $\mathrm{K}$, et al: Pontine cavernous angioma resected using the subtemporal, anterior transpetrosal approach determined using three-dimensional anisotropy contrast imaging: technical case report. Neurosurgery 58 (1 Suppl): ONS-E175, 2006

13) King WA, Black KL, Martin NA, et al: The petrosal approach with hearing preservation. J Neurosurg 79: 508-514, 1993

14) Linsler S, Oertel J: Endoscopic endonasal transclival resection of a brainstem cavernoma: a detailed account of our technique and comparison with the literature. World Neurosurg 84: 2064-2071, 2015

15) MacDonald JD, Antonelli P, Day AL: The anterior subtemporal, medial transpetrosal approach to the upper basilar artery and ponto-mesencephalic junction. Neurosurgery 43: 8489, 1998

16) Matsushima $\mathrm{T}$, Abe $\mathrm{H}$, Kawashima, et al: Exposure of the wide interior of the fourth ventricle without splitting the vermis: importance of cutting procedures for the tela choroidea. Neurosurg Rev 35: 563-572, 2012

17）森迫拓貴, 渡部祐輔, 中条公輔, ほか：脳幹部橋海綿状血管 腫に対する経錐体到達法の有用性. 脳卒中の外科 45: 260265, 2017

18) Oiwa Y, Nakai K, Masaki Y, et al: Presigmoid approach for cavernous angioma in the pons-technical note. Neurol Med Chir (Tokyo) 42: 91-96, 2002

19) Recalde RJ, Figueiredo EG, de Oliveira E: Microsurgical anatomy of the safe entry zones on the anterolateral brainstem related to surgical approaches to cavernous malformations. Neurosurgery 62 (3 Suppl 1): 9-15, 2008

20) Saito N, Sasaki T, Chikui E, et al: Anterior transpetrosal approach for pontine cavernous angioma-case report. Neurol Med Chir (Tokyo) 42: 272-274, 2002

21) Sanborn MR, Kramarz MJ, Storm PB, et al: Endoscopic, endonasal, transclival resection of a pontine cavernoma: case report. Neurosurgery 71 (1 Suppl Operative): 198-203, 2012

22) Seifelt V, Raabe A, Zimmermann M: Conservative (labyrinthpreserving) transpetrosal approach to the clivus and petroclival region-indications, complications, results and lessons learned. Acta Neurochir (Wien) 145: 631-642, 2003

23) Spetzler RF, Daspit CP, Pappas CT: The combined supra- and infratentorial approach for lesions of the petrous and clival regions: experience with 46 cases. J Neurosurg 76: 588-599, 1992

24) Steiger HJ, Hänggi D, Stummer W, et al: Custom-tailored transdural anterior transpetrosal approach to ventral pons and retroclival regions. J Neurosurg 104: 38-46, 2006

25) Viñas FC, Gordon C, Guthikonda M, et al: Surgical management of cavernous malformations of the brainstem. Neurol Res 24: 61-72, 2002

26）横山邦生, 川西昌浩, 山田 誠, ほか：前経錐体到達法で摘 出した橋腹側海綿状血管腫の 1 例. 脳卒中の外科 45: 266269, 2017 